\title{
Research on Rural Tourism Driving Transfer of Surplus Rural Labor Force in Hainan Province
}

\author{
Mingju Liu \\ Yatai School of Business Administration \\ Jilin University of Finance and Economics \\ Changchun, Jilin, China 130117
}

\author{
Liguang Zhao \\ School of Taxation \\ Jilin University of Finance and Economics \\ Changchun, China 130117
}

\author{
Meijiao Huang \\ Yatai School of Business Administration \\ Jilin University of Finance and Economics \\ Changchun, Jilin, China 130117
}

\begin{abstract}
The rapid development of rural tourism can promote economic development. Meanwhile, it also provides more employment post and solves surplus rural labor forces. This article takes Hainan province as an example, analyzes promotion effect of rural tourism on transfer of surplus rural labor force, points out the main factors that influence rural tourism to drive transfer of surplus rural labor forces include comprehensive quality of labor force, operating cost and innovation risk, tourist income and government guidance, puts forward related countermeasures that help surplus rural labor forces to transfer to rural tourism, which has very important guiding significance on research on rural tourism in Hainan province to drive the transfer of surplus rural labor forces.
\end{abstract}

Keywords-rural tourism; surplus rural labor force; Hainan province; transfer; countermeasures

\section{INTRODUCTION}

With rapid development of tourism industry, as an important branch of tourism industry, rural tourism makes great contributions for construction of new socialist countryside of our country. In 2006, Hainan province put forward to construct Hainan into the preferred destination of rural recreational tourism of our country. In 2009, the State Council issued "Some Opinions on Promoting Construction and Development of Hainan International Tourism Island", which provided opportunity for rural tourism development. Make use of rich tourism resources of Hainan province, use policies to support and develop rural tourism, make more rural labor force transfer in their local place, increase employment opportunity, give play to important effect on constructing harmonious society and promoting new rural construction and provide more ways to realize effective transfer of a large number of surplus labor forces in rural areas.

Fund programs: National Natural Science Foundation of China (project number: 41401146); Social Science Funding Project in Jilin Province (2015BS40); Scientific and Technological Development Planning Project in Jilin Province (201502040NY)

\section{CURRENT SituATION AND AdVANTAGE OF RURAL TOURISM DEVELOPMENT IN HAINAN PROVINCE}

\section{A. Current Situation of Rural Tourism Development in Hainan Province}

The rural tourism of Hainan province burgeoned in the middle of 1990s. Now the self-development pattern of it has taken the initial shape. In October 2013, in order to promote overall development of urban-rural integration of Hainan province and construction of socialism new countryside as well as new-type urbanization construction, it will bring better development opportunity for rural tourism, which serves as an important part of international tourism island construction.

At present, there are six cities and counties and more than 30 villages in Hainan province that have carried out rural tourism. There are 516 rural-tourism spots in the whole province that serve as demonstration. Bereng Village has the honor to get the title of the first batch of "China Rural Tourism Makers Demonstration Base". According to statistics, in 2015, the rural tourism in the whole province accepted tourists of $6,748,500$. The total income of rural tourism is 1.775 billion yuan. It is predicted that it will accept tourists of 13,670,000; the gross revenue of tourism industry reached 3.5 billion in 2015 . It will reach 11.1 billion yuan in 2020 . It is easy to see from these achievements that the rural tourism in Hainan develops and grows continuously.

\section{B. Advantages of Hainan Province to Develop Rural Tourism}

As the second big island of China, Hainan province is located in the southernmost of China and the north edge of tropic. It has very rich natural resources and human resources, unique ethnic culture, natural landscape different from other parts of the country and comfortable climate, which are favorable factors for Hainan province to develop rural tourism.

1) Unique tropical idyllic scenery: Hainan is the only sea island of our country that has tropical and subtropical climate. 
It is the tropical seashore tourist resort that gains popularity of domestic and foreign tourists. It has good ecological environment and unique tropical tourism resources. Hainan belongs to tropical monsoon climate without winter. It is known as the good name of "natural big greenhouse" with forest coverage rate of $60.2 \%$, which is ranked the second of our country. It is called as "back garden" of the mainland, "Chinese Hawaii", "Pollution-free Island" and "Longevity Island" and has unique tropical scenery of China.

2) Colorful national customs: Hainan province has more than 30 nationalities including $\mathrm{Han}, \mathrm{Li}$, Miao and Hui. Li nationality is the aboriginal nationality of Hainan. They inhabit in Southwest of Hainan province and Five Finger Mountain area located in middle of Hainan province for generations. For thousands of years, it forms unique national customs with primitive simplicity, unique ecological and cultural environment, rich folk culture and historic culture. The Li Miao culture is a miracle, which has great appeal for tourists who are eager to feel different folk culture.

3) Rich and varied rural tourism resources: There are 440 rural tourism resource points in total in Hainan province, which occupy five main types, 25 subclasses and 63 basic types. The total quantity of rural natural ecological landscape resource points is 54 , which occupies $12.27 \%$ of the quantity of total resource point; the quantity of rural countryside landscape resource point is 75 , which occupies $17.05 \%$ of the quantity of total resource point; the quantity of rural heritage and architecture landscape resource point is 221, which occupies $50.23 \%$ of the quantity of total resource point; the quantity of rural humanity activity and folk culture resource point is 60 , which occupies $13.64 \%$ of the quantity of total resource point; the quantity of rural tourist commodity resource point is 30, which occupies $6.82 \%$ of the quantity of total resource point. This shows that the rural tourism resources in Hainan province are rich and diversified with plenty number and wide range of types.

4) Superior geographic position and broad tourist market: Hainan province is the province located in the southernmost of China, with good reputation of "Tianya Haijiao". Hainan and many countries of Southeast Asia are separated by sea. Because Hainan has warm climate at all seasons and beautiful environment, it is the first choice for many tourists to preserve their health and escape cold. There are about more than two million urban residents in Hainan. Many pay a visit to villages on leisure time and holidays. The operation of eastern, central and western expressway networks of Hainan Island, eastern and western high speed railway makes the transportation of Hainan Island become very convenient and gradually forms "one hour life circle". Hainan province has market in the province and our country as well as overseas market. It shows that rural tourism in Hainan province has broad tourist market.

5) National policy advantage is obvious: Hainan province is the largest special economic zone of our country. Tourism industry has the highest proportion in the three main industries of Hainan. In 2008, the State Council agreed
Hainan province to construct "International Tourism Island". In order to truly construct international tourism island, our country gives a series of preferential policies, such as exempt tax refund in shopping. The State Council also ratifies four cities in Hainan to open duty-free shop. Preferential policies endowed by our country for construction of international tourism island also include visa-free entry for 26 countries, cruise and yacht tourism. These preferential policies make the quantity of tourists in Hainan increase sharply and also provide development opportunity for tourism industry of Hainan province.

\section{PROMOTION EFFECTS OF RURAL TOURISM DEVELOPMENT ON SURPLUS RURAL LABOR FORCE TRANSFER}

Tourism industry is labor intensive industry and has obvious effects to absorb rural labor forces. The employment posts have low requirements. It has great demand for labor forces at different levels. Especially in fields such as transportation, catering, merchandise, scenic spot, travel agency and tour guide that are related to tourism industry, most employment posts have no demanding requirements for degree of education, gender and age. It is very appropriate for local transfer to surplus rural labor forces.

\section{A. Increase Employment Post and Enlarge Employment Groups}

As a kind of labor intensive industry, rural tourism has not high requirements for labor force and low employment threshold, strong inclusiveness. It is absolutely an all-right employment choice for rural labor forces with not high overall quality. The employment of traditional surplus rural labor forces mainly centers on the second and third industries with great demand for labor forces. It has requirements for gender, age, cultural quality and skill of surplus rural labor force. With development of rural tourism industry, it doesn't require people to have high professional qualification, without limitation for gender, age and health degree. No matter young adults and housewives without technical expertise or children and the aged without labor capacity can engage in tourism service, produce and process distinctive agricultural products, handiwork and souvenir, such as the processing of coconut handicrafts and plantation of coconut and mango, then directly sell them to tourists. The development of rural tourism in Hainan province greatly absorbs surplus rural labor force, enlarges employment groups, avoids wasting and leaving human resources unused and makes people on Hainan Island can make contributions for jointly walking towards the road to affluence.

\section{B. Reduce Employment Cost and Increase Economic Income}

Rural tourism takes rural areas as tourism destination. The rural tourism development helps local transfer to surplus rural labor force of Hainan province. It not only saves expenses such as transportation expense and hotel expense cost by rural labor force to work outside Hainan province, but also saves unnecessary expenses of psychological capital, human capital and social capital. Rural tourism doesn't have high requirements for capital investment, technology, skill and 
quantity of capital investment of employees. So if it has land, capital and training of technicians, farmers in Hainan can carry out rural tourism business. In addition, rural tourism hasn't low and peak seasons for tourism in ordinary days, holidays and festivals and four seasons. It will not influence agricultural production in ordinary days. Besides, it can let agricultural products in Hainan move towards the market directly, and avoid losses brought by intermediate links, increase incomes. It neglects neither the development of rural tourism nor agricultural production and directly promotes increasing income of farmers. The living standard of farmers also improves continuously.

\section{Drive the Development of Related Industries and Promote Rural Economic Development}

The development of tourism will drive the development of six industries such as "eating, accommodation, transportation, traveling, shopping and entertainment" in Hainan province. Rural tourism and rural industry penetrate mutually and have close relationship. The development of rural tourism will drive the development of agriculture and related industries in rural areas, then increase employment opportunities for surplus rural labor force, stabilize their employment situation and accelerate promoting the transfer and employment of surplus rural labor forces. The development of rural tourism has very important significance on increasing income of farmers and accelerating rural economic development in Hainan and building well-off society in an all-round way. Moreover, farmers in Hainan seize the development opportunity to strive to improve their cultural quality and professional competence. Some advanced and unique ideology in cities and latest information in society are also brought to farmers through rural tourism. It not only influences backward traditional ideas of farmers but also broadens horizons of farmers. Besides, it will create a generation of new type farmers with quality and culture.

\section{FACTORS THAT INFLUENCE RURAL TOURISM TO DRIVE THE TRANSFER TO SURPLUS RURAL LABOR FORCES}

\section{A. Comprehensive Quality of Labor Force}

In recent years, the development of tourism industry of Hainan has obtained some achievement. However, it also has the phenomenon that local people in Hainan tourist attractions swindle money out of tourists from other places. The service quality in tourism is questioned by tourists continuously. Most rural labor forces have conservative thoughts. They do not have corresponding courage and insight and management strategies for development opportunities brought by tourism industry but put profit first. With low educational level and poor ability to learn, it is difficult for them to accept knowledge on management and acceptance related to rural tourism. Besides, they are always content with things as they are and wait for customers at home instead of carrying out relevant marketing publicity, do not consider the continuous development of rural tourism and take rural tourism as a career that may changes their destiny. All of these go against longterm and stable employment of rural labor forces in rural tourism.

\section{B. Operational Cost and Entrepreneurial Risk}

According to related investigations, rural tourism absorbs rural labor forces mainly through self-employment. Most of them work on happy farmhouse that centers on the family. So relevant operating cost is paid by themselves of course. The main income sources of farmers in Hainan are rubber, planting industry and breeding industry. It is impossible for farmers with conservative thoughts to bear the high risk brought by entrepreneurship. In recent years, Hainan quickens the pace to construct international tourism island. Cities and counties in Hainan make contributions for international construction of Hainan. Farmlands of many farmers are expropriated by the government for construction of highway and railway as well as real estate development. Although farmers get respectable compensation payments from the government, most farmers use the money to build the house. Because they are content with things as they are and unwilling to bear the risks brought by entrepreneurship, there are few family spending the money in entrepreneurship. Therefore, it is of no help even though they know that developing rural tourism can transfer surplus rural labor forces.

\section{Tourist Income}

Tourist income has relationship with immediate interest of rural labor forces. They pay the most attention to it. Rural labor forces in Hainan province are mainly employed in service industry, building industry and agricultural industry and have not high economic income. Through developing rural tourism, farmers can sell local agricultural and sideline products at home. For families and labor forces that directly engage in reception of accommodation and catering, as well as labor forces with professional skills, they will have higher income. Income is the main factor to influence transfer of rural labor force. Once the earnings brought by rural tourism is lower than the income of employment posts that other industries can provide for them, it will drive rural labor forces to transfer to other places.

\section{Government Guidance}

The principal part to develop rural tourism is farmers. They have inadequate understanding for management and service of rural tourism. If the government does not guide and manage and the rural tourism is developed by rural labor forces randomly, it is very likely to appear the chaotic phenomenon of rural tourism business. For example, strawberry fields of many happy farmhouses in Danzhou city of Hainan province meet the requirements of tourists to pick strawberries in strawberry field in person by letting strawberries to bear fruits as soon as possible. It is well-known throughout the country that the list price of dishes in happy farmhouses of Sanya is confused. If the government does not supervise and manage forcibly, it will go against the development of rural tourism. Rural tourism is more willing to employ local people. It is obvious that if the development of rural tourism has not correct guidance, supervision and management, it will develop chaotically. Its effect on absorbing rural labor forces will decrease. 


\section{COUNTERMEASURES FOR HAINAN PROVINCE TO PROMOTE RURAL TOURISM TO ABSORB SURPLUS RURAL LABOR FORCES}

\section{A. Carry out Skill Training and Cultivate New Generation of New Type Farmers with High Quality and Skills}

Although rural tourism does not have high requirements for labor forces, the quality, knowledge and education level of farmers have important relationship with transfer of surplus rural labor forces. At present, there isn't training class related to special skill training of tourism industry. The government and education department can arrange regular training courses, open training courses related to leisure agriculture and rural tourism, impart professional knowledge, new management and service concepts for them. Meanwhile, government or private person or non-state institutions can invest and run tourism training schools in rural areas, provide more opportunities for rural labor forces to learn. It helps to solve the problem that rural tourism development has demand for talents and provide conditions for cultivating new generation of new type farmers with high quality and skills.

\section{B. Arouse Enthusiasm of Farmers to Participate in Rural Tourism}

Living habits of farmers in Hainan is relatively relaxed and free. They advocate carefree and content pastoral life as Tao Yuanming lives. They cannot bear hardships and stand hard work, lack the consciousness of becoming rich, be content with the status quo and have not spirit of adventure. Therefore, in order to better and faster develop rural tourism, the first step is to improve enthusiasm of farmers to participate in it. The government shall enlarge propaganda work for rural tourism, designate specialized persons to go to the countryside to narrate and publicize and eliminate concerns of rural labor forces for operating rural tourism. In addition, the government can lead a few people to play the demonstration role in operating rural tourism to become rich, actively guide and encourage a growing number of farmers to participate in tourism management activities then accelerate development of rural tourism.

\section{Insist on Government Leadership and Increase Investment}

It is also the important responsibility of government to further make rural tourism bigger and stronger, solve the employment problem of surplus rural labor force and make contribution for the solution of issue concerning "agriculture and countryside and farmers". Insist government leadership for rural tourism planning in Hainan province, increase rural tourist spots, insist government leadership for land acquisition of rural areas, insist government leadership for infrastructure construction of rural tourism area, standardization of reception services facilities, insist government leadership for development of investment promotion for rural tourism, insist government leadership for beautification of service environment and protection of natural environment in rural areas. Through government leadership, reinforce financial support for rural areas, actively guide enterprises to invest in rural tourism and eliminate financial pressure and worries of rural labor forces in developing rural tourism. Government shall not only give support on financial resources, but also strengthen supervision of rural tourism, improve rural tourism management, introduce in modern concept of enterprise management, implement systematic and integral management, resolutely prevent behaviors such as management fraud and unfair competition as well as safeguard rights and interests of consumers and investors, guide operators of rural tourism to manage sincerely, improve quality of service and develop rural tourism.

\section{Adjust Industrial Structure of Rural Areas}

Rural tourism is a comprehensive industry, with high industry related degree and wide industry leading effect. It requires rural tourism development to carry out matching development with related industry to adjust industrial structure of rural areas. Rural labor forces will find broader employment space in adjustment of rural industry.

Through development of rural tourism, take tourist market requirements as the direction, develop characteristic planting industry and special livestock breeding, form new pattern of agricultural production, drive the development of relevant industries through rural tourism, gradually raise the proportions of secondary industry and tertiary industry in rural areas and realize letting more rural labor forces transfer from primary industry to secondary and tertiary industries in local places.

\section{E. Build Unique Brand and Strengthen the Appeal of Tourism}

The development and construction of rural tourism shall make the most of superior original ecological natural resources and unique cultural tourism resources of $\mathrm{Li}$ and Miao ethnic minorities, build particular brand image of rural tourism on Hainan Island and develop more characteristic rural tourism products. Hainan devotes to build "good taste" rural tourism products. Now Hainan province has developed rural tourism products with brand characteristics. For example, Wenchang Hulu village with characteristics of local culture shows tourists with original ecological rural tourism products that "can see nostalgia". Besides, the development of a series of rural tourism brands such as Dingan Bailibai village and Wenchang Longquanxiang Manor actively promote the construction of rural tourism brand in Hainan province and strengthen the appeal of rural tourism in Hainan province.

\section{REFERENCES}

[1] Cai Renguang. Research on Financial Support Policy for Rural Tourism in Hainan under International Tourism Island [D], Guilin University of Technology, 2013.

[2] Zhang Hongliang. Research on Influence of Rural Education Investment in Hainan on Transfer of Surplus Rural Labor Force [D], Hainan University, 2012.

[3] Yin Changfeng, Liu Baiping. Research on Value of Rural Tourism and Surplus Rural Labor Force Transfer-Take Hefei as an Example [J], Management Modernization, 2010, (08). 36-38.

[4] Zeng Feng. Research on Tropical Agricultural Ecological Tourism Development of Agricultural Reclamation in Hainan under the Perspective of International Tourism Island [J], Ecological Economy, 2010, (02) 102-105. 
[5] Yu Hao. Research on Promotion Function of Rural Tourism Development on Surplus Rural Labor Force Transfer [J], Guizhou Normal University, 2009.

[6] Meng Hui. Research on Developing Rural Tourism to Promote Transfer of Surplus Rural Labor Force-Take Guihou as an Example [J], Tourism Overview (the Second Half of the Month), 2014, (07).

[7] Chen Ruxi. Current Situation and Development of Rural Tourism in Our Country under the Background of New Rural Construction $[\mathrm{J}]$, Agricultural Economy, 2011, (12), 19-20.

[8] Liu Mingju. Research on Competitive Advantage of Rural Tourism Development in Jilin Province [J], Agricultural Economy, 2014, (05), 43-45. 